\title{
Initiating end-of-life decisions with parents of infants receiving neonatal intensive care
}

Chloe Shaw $^{\mathrm{a}^{*}}$, Kathrina Connabeer ${ }^{\mathrm{b}}$, Paul Drew ${ }^{\mathrm{c}}$, Katie Gallagher ${ }^{\mathrm{a}}$, Narendra Aladangady ${ }^{\mathrm{d}}$, Neil Marlow $^{\mathrm{a}}$

a. UCL EGA Institute for Women's Health, University College London, London, UK chloe.shaw@ucl.ac.uk, katie.gallagher@ucl.ac.uk,n.marlow@ucl.ac.uk

b. Birmingham City University, Birmingham, UK

Kathrina.Connabeer@bcu.ac.uk

c. Department of Language \& Linguistic Science, University of York, York, UK paul.drew@york.ac.uk

d. Department of Neonatology, Homerton University Hospital, London, UK AND Centre for Paediatrics, Barts and the London School of Medicine and Dentistry, QMUL, London, UK

n.aladangady@nhs.net

*Corresponding author at: UCL EGA Institute for Women's Health, University College London, Medical School Building, 74 Huntley Street, London, WC1E 6BT UK

chloe.shaw@ucl.ac.uk

\section{Conflict of interest}

All authors declare no direct conflict of interest. NM declares personal fees for consultancy from Shire and Novartis outside the submitted work.

(C) 2020 This manuscript version is made available under the CC-BY-NC-ND 4.0 license http://creativecommons.org/licenses/by-nc-nd/4.0/ 


\section{Abstract}

Objective: To investigate whether parent-initiated or doctor-initiated decisions about limiting lifesustaining treatment (LST) in neonatal care has consequences for how possible courses of action are presented.

Method: Formal conversations $(n=27)$ between doctors and parents of critically ill babies from two level 3 neonatal intensive care units were audio or video recorded. Sequences of talk where decisions about limiting LST were presented were analysed using Conversation Analysis and coded using a Conversation Analytic informed coding framework. Relationships between codes were analysed using Fisher's exact Test.

Results: When parents initiated the decision point, doctors subsequently tended to refer to or list available options. When doctors initiated, they tended to use 'recommendations' or 'single-option' choice (conditional) formats $(p=0.017)$ that did not include multiple treatment options. Parent initiations overwhelmingly concerned withdrawal, as opposed to withholding of LST ( $p=0.030)$. Conclusion: Aligning parents to the trajectory of the news about their baby's poor condition may influence how the doctor subsequently presents the decision to limit LST, and thereby the extent to which parents are invited to participate in shared decision-making.

Practice implications: Explicitly proposing treatment options may provide parents with opportunities to be involved in treatment decisions for their critically ill babies, thereby fostering shared decisionmaking.

\section{Key words}

Decision making, neonates, end-of-life, conversation analysis, parents, withdrawing, withholding

\section{Funding}

The research was supported by Sands, the stillbirth and neonatal death charity, and in part by National Institute of Health Research (NIHR) Programme Development Grant RG-DG-061110006. The funders played no role in the study design; in the collection, analysis and interpretation of data; in the writing of the report; or in the decision to submit the article for publication. Neil Marlow receives part funding from the Department of Health's NIHR Biomedical Research Centre's funding scheme at UCLH/UCL. 


\section{Introduction}

Parents whose babies are being treated in neonatal intensive care find it a profoundly emotional and stressful experience. [1-3] For parents facing decisions about the possibility of redirecting intensive care to palliative care, their experience may become particularly traumatic. Such decisions may arise when a baby is recognised to have a poor prognosis because of brain injury, for example following extremely premature birth or a severe lack of oxygen during labour, or with severe congenital anomalies. [4] Decisions to limit life-sustaining treatment may be considered when there is expected to be limited survival or quality of life. [5] Doctors are guided by the Royal College of Paediatrics and Child Health (RCPCH) framework, based on an assessment of the best interests of the baby; however such an assessment is not necessarily-clear cut but is often based on risk rather than certainty.[5] The clinical situation may be uncertain and there may be uncertainty surrounding what is the right thing to do.[6] Decisions about 'best interest' can therefore involve value judgments about likely quality of life, which may result in differing perspectives both within the medical and nursing team, [6-8] and between doctors and parents. [5] [9]

Involving parents in the decision-making process is crucial both ethically and legally. "Best interests' are not purely confined to considerations of best medical or clinical interests, but include other medical, social, emotional and welfare factors" [5] [PS9]. The judgement about the baby's best interest requires the parents' perspective; doctors are required to obtain the parents' consent for treatment.[5] It is clear that parents want to and should be involved in the decision-making process. [10] [5] One study in France demonstrated that parental perception of a shared end-of-life decision, compared with paternalistic decision making or making the decision on their own, was associated with significantly lower grief scores on long term follow-up.[11]

How the involvement of parents in decision-making is managed is insufficiently understood. The Nuffield Council of Bioethics emphasises the importance of considering "what shared decision making looks like in practice" (Nuffield Council on Bioethics, 2019: 6). A small number of observational studies have examined what actually happens in neonatal consultations. [12-14] Boss et al. coded neonatal conversations for the presence and absence of different aspects of medical and psychosocial talk and questioning. They found minimal talk focused on the psychosocial domain and only 5\% of talk comprised parents' questions. [13] De Vos et al. examined audio recordings of end-of-life decision making in paediatric intensive care in the Netherlands and identified ways in which doctors engaged (or did not) in shared decision-making with parents.[12] They found that parent involvement in decision making was mostly through the initiative of parent questions and putting forward their preferences without these being elicited by the doctor. [12] While these studies have demonstrated in broad terms that doctors' talk has consequences for 
parental involvement, we used the method of conversation analysis to focus on precisely how the design of the doctors' talk enabled or hindered parental participation.[14]

Building on our previous work investigating the decision-making process, [14] in this phase of our research we address how parents and doctors come to a decision point. We focus specifically on who initiated the decision - whether the doctor or parents initiated the point at which the possibility of a decision is broached.

\section{Methods}

\subsection{Participants and procedure}

Data were collected from two Level 3 neonatal intensive care units in England. The formal conversations (away from the cot side) of parents of critically ill babies and doctor were audio (Site 1, 2013-2014) or video (Site 2, 2015-2016) recorded. From a total of 51 families recruited to the study, we identified 21 families and 27 conversations in which the possibility of limiting lifesustaining treatment was presented to the parents, excluding cases where decisions were not made explicit. There were nine conversations with one parent present and 18 with both parents present. The conversations involved 14 different consultants. The reasons for considering limiting lifesustaining treatment were: severe perinatal asphyxia $(n=4)$, prematurity with neurological complications $(n=6)$, very premature infant with an iatrogenic problem $(n=1)$, complex congenital (including cardiac) anomalies ( $n=8)$, threatened preterm delivery of twins at 23 weeks gestation (one baby with ruptured amniotic membranes) $(n=1)$, and perioperative neurological insult $(n=1)$. Table 1 summarises key parent and infant demographics.

Table 1: Summary demographics of the 20 babies and one unborn foetus ( 21 discrete families)

\begin{tabular}{|l|l|l|}
\hline Infant Sex & Male & 13 \\
\hline Gestation & Median (Range) & $35(23-41)$ weeks \\
\hline & $<32 \mathrm{w}$ & 8 \\
\hline & $32-36 \mathrm{w}$ & 4 \\
\hline & Term & 9 \\
\hline Birthweight $*$ & Median (Range) & $2145(630-3880)$ grams \\
\hline & $<1500 \mathrm{~g}$ & 7 \\
\hline & $1500-2499 \mathrm{~g}$ & 9 \\
\hline & $>2500 \mathrm{~g}$ & 4 \\
\hline Ethnic group $* *$ & 7 \\
\hline & Black & 11 \\
\hline & Caucasian & 2 \\
\hline Spiritual beliefs $* * *$ & other & 5 \\
\hline & None declared & 2 \\
\hline & Muslim & 9 \\
\hline & Christian & 1 \\
\hline$* 1$ unborn; $* * 1$ not recorded; $* * * 4$ not recorded; & \\
\hline & Other & \\
\hline
\end{tabular}




\subsection{Analytic procedure}

Qualitative analysis. Recordings were transcribed in detail, to capture the relative timing of talk (pauses, overlapping speech) and characteristics of speech delivery (intonation, prosody).[15] The segments identified were analysed using conversation analysis (CA), focusing on the sequential management of talk, including action, turn design, sequential context, and how conversations subsequently unfold. $[16,17]$ We identified those segments in which doctors presented a decision to limit life-sustaining treatment, then analysed more specifically i) who initiated the decision point and ii) how they did so (linguistic format).

Quantitative analysis. The segments described above were coded using a CA informed coding framework, (see [18] for an example of a CA informed coding framework) capturing details of the way in which decisions were presented and the opportunity these afforded to parents to respond (see [19]). A sample of 14 conversations were coded by two independent coders. Cohen's Kappa was used to measure the interrater reliability of the codes across the two coders' scores, for whether the parent(s) or doctor initiated the decision point. Fisher's Exact Test was used to calculate the relationship between who initiated decision-making and how the decision was then presented by the doctor. This test was considered appropriate for a small sample.

\subsection{Ethics}

The study received approval from the London - City and East Research Ethics Committee and the Research \& Development Departments of participating NHS Trusts. Parents and consultants gave written informed consent for their conversations to be recorded for research purposes; transcripts have been anonymised.

\section{Results}

\subsection{Who initiates decision-making}

We define as decision points, those points at which either a parent or doctor moves to consider (initiates) what decision should be made about the baby's treatment. Sequences were coded in terms of whether the parent or doctor initiated the decision point. Doctors tended to initiate decision points more frequently $(n=19)$, than parents $(n=8)$.

Decision points arose subsequent to the doctor providing information about the baby's poor condition or prognosis. Parents tended to initiate the decision point by enquiring about future courses of action, either by asking the doctor 'what next' $(n=6)$, or by themselves indicating their preference for a future course of action $(n=2)$. 


\section{Extract 1 [S2F13R1]}

1 Dr: The tube, (0.4) just drains the pressure $>$ it doesn' $t<(0.7)$

2 treat the brain tissue itself.

$3 \quad(2.1)$

$4 \quad \mathrm{M}: \quad>$.hh< (0.8) .hh (0.6) .HHHHHH (0.2) HHHHHH. (12.2) so (0.5)

$5 \quad$ w-w-w-what's next.

$6 \quad(0.5)$

7 Dr: Well, (0.8) we don't need to make any urgent decisions but,

$8 \quad$ (1.4) one option, in this situation (0.6) is to, (0.5)

9 consider whether it's actually right to continue with the

10 intensive care support that she's, (0.4) she's having.

The doctor reported that the baby is deteriorating, and therefore that a tube might be inserted to drain the pressure from the brain, though that is unlikely to "save the brain" (data not shown). The mother asked "So what's next" (lines 4-5), thereby explicitly making relevant a decision about future courses of action or treatment. The doctor responds in lines 7-10 by introducing and outlining one decision option for the future (whether to continue with intensive care support).

Parents also, though rarely, initiated decision points by explicitly stating a treatment preference, as in the extract below.

\section{Extract 2 [S2F10R2]}

\begin{tabular}{|c|c|c|}
\hline 1 & Dr: & ...an' I think it's very likely that he would have, $(0.3)$ some \\
\hline 2 & & very important (.) long-term, (0.5) consequences an' \\
\hline 3 & & handicap, (.) an' that if he was able- (0.4) come through \\
\hline 4 & & this- (1.6) an'- (0.4) by that, I mean I think it's very \\
\hline 5 & & likely that he'd have cerebral palsy. \\
\hline 6 & & (1.1) \\
\hline 7 & Dr: & ${ }^{\circ} \mathrm{Uh}^{\circ}(0.3)$ probably be a severe type so= \\
\hline 8 & $\mathrm{~F}:$ & $=$ From what $(0.3)^{\circ}$ we $^{\circ}(0.3)$ we've talked about it wi' two of \\
\hline 9 & & us to some exte:nt. \\
\hline 10 & & $(3.1)$ \\
\hline 11 & $\mathrm{~F}:$ & AN:DHH. (0.3) (.snff) (0.9) to try a' put in a nutshell \\
\hline 12 & & 'cause I- obviously not being very (1.4) if there's 个anything \\
\hline 13 & & can be do:ne, (0.6) even if it was a lifetime in a wheel \\
\hline 14 & & chai:r \\
\hline 15 & Dr: & Yeah, \\
\hline 16 & & $(0.4)$ \\
\hline 17 & $\mathrm{~F}:$ & It's better than \\
\hline
\end{tabular}

The doctor has informed the parents that the baby's MRI scan revealed severe brain injury, outlining the likely consequences for the baby's development (lines 1-7). The father responded by indicating a preference that pushes back against the implication that life-sustaining treatment might be limited, 
"if there's anything can be done" (lines 12-13). The anticipated decision (i.e. to limit life supporting treatment) is thereby pre-empted by the father, before the doctor had the chance to suggest it.

To summarise, parent decision-initiations either 1 ) enquire about treatment possibilities or 2) state a preference for a particular course of action.

Doctor-initiated decision points also tended to follow information about the baby's poor condition, but without the parents having enquired about future courses of action.

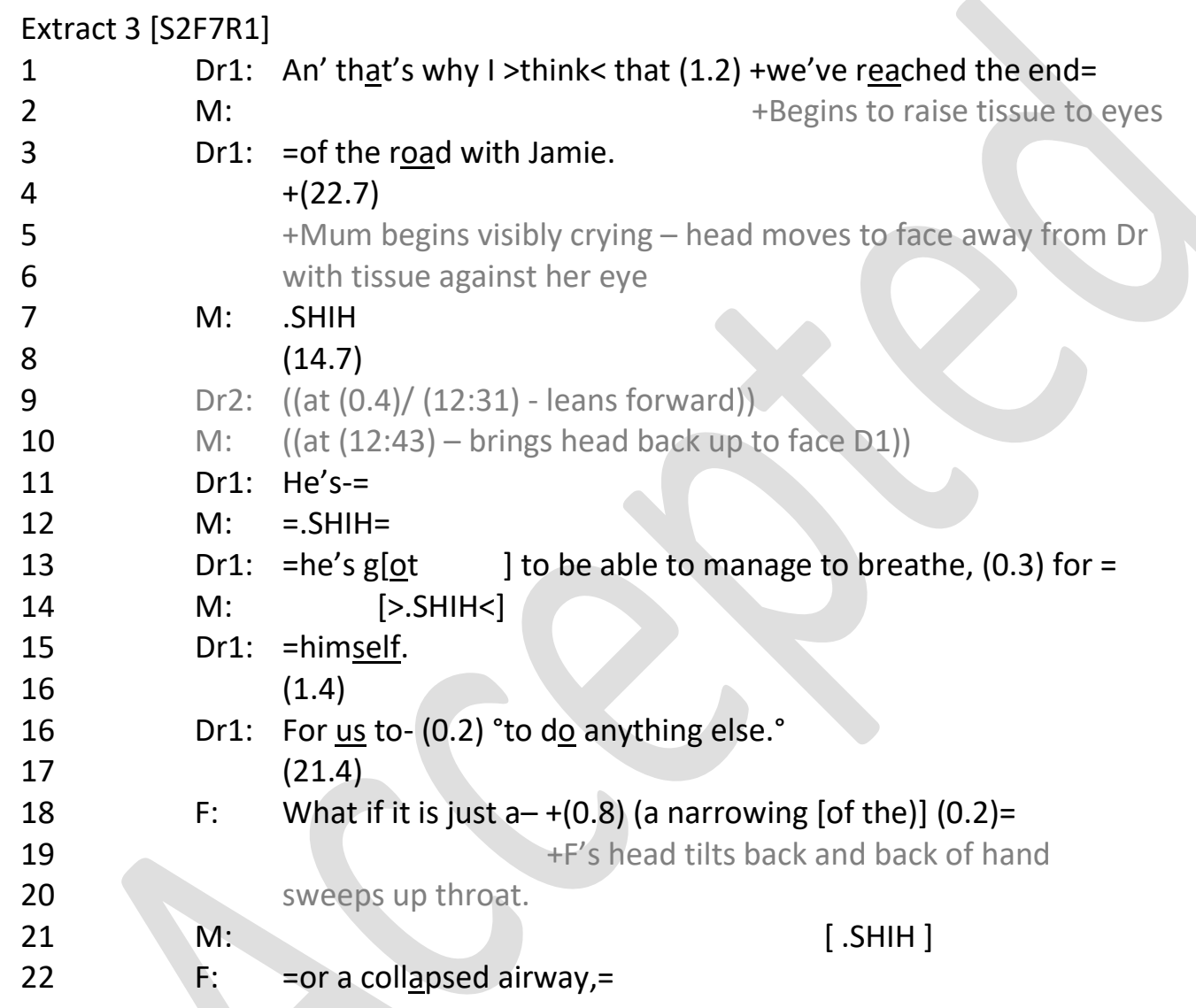

((20 lines omitted where Dr1 explains that they had hoped the bronchoscopy would have confirmed the problem was to do with the baby's airway, but it did not.))

43 Dr1: So we're, (1.9) stuck at the point where, (0.9) it looks like it should work, (1.7) but he can't manage.

(4.3)

Dr2: +Suppose the 个other important thing is to raise you know $+D 2$ sits forward as he begins to talk

as, (0.2) intensive care doctors we always have to try an'assess, (1.2) what- (0.3) what pa:in what the patient's going through an' whether it, (1.0) that's (1.1) > what M: he's< going through now is, (0.6) [ just]ifiable if it's=

53 Dr2: =as good as hope of improvement in the future. $=A n^{\prime}$ 


\begin{tabular}{|c|c|c|}
\hline 54 & & obviously up to now we've been trying everything- $+(0.5)$ we \\
\hline 55 & & $+\mathrm{M}$ nods \\
\hline 56 & Dr2: & can with Jamie (0.7) we continue to do so but, . $\mathrm{HHH}(0.8) \mathrm{I}$ \\
\hline 57 & & think, $(0.5)$ if he's not showing, $(0.4)$ the ability to come \\
\hline 58 & & off the ventilator we do need to consider, $(0.8)$ what he's \\
\hline 59 & & going through no:w, an' what he'd have to go through in the \\
\hline 60 & & future. ${ }^{\circ}$ In terms of treatment. ${ }^{\circ}$ \\
\hline
\end{tabular}

The surgeon is approaching the end of delivering the news that if the baby cannot manage to breathe without mechanical support, they cannot operate on the baby's heart. After a 4.3 second silence (line 45), the neonatologist then both initiates and presents a hypothetical, future oriented decision concerning the limitation of life-sustaining treatment. Following this news about a poor prognosis, the parents did not ask about future courses of action.

\subsection{Recommendations, 'single-option choice format' or option listing?}

In addition to who initiated the decision point, sequences were coded for how the decision was presented (i.e. the linguistic format through which possible future courses of action were presented, akin to the treatment decision formats reported by Stivers et al. [20]). We identified three types of decision formats: recommendations (one course of action is presented and explicitly endorsed as the best course of action); a 'single-option' choice (conditional) format (referring to a choice that should be made, but without specifying or listing options), and options (the doctor explicitly refers to or lists options).

The differences between these decision formats are illustrated in these brief extracts, one of each format. In this first excerpt, the doctor recommends a clear course of action, that we should offer to palliate him and to discontinue intensive care.

Extract 4 (Recommendation)

$\begin{array}{lll}1 & \text { Dr: } \quad<\text { And }>>\text { I think< our feeling as a tea:m, is that- }(0.4) \text { we should, } \\ 2 & & \begin{array}{l}(1.2) \text { offer, (.) to: }(0.2) \text { palliate him an' to, (0.4) discontinue } \\ 3\end{array} \\ 4 & \text { intensive care. } \\ 5 & \text { Dr: } \quad \begin{array}{l}\text { I think that would be in his best interest.=(and ultimately) he } \\ 6\end{array} & \text { would (0.3) he would die. }\end{array}$

Note that the doctor presents this as a recommendation supported by the team; and that the parents are not included in this decision process. However, it should be noted that the strength of the recommendation is mitigated by the doctor's reference to offering the parents this course of 
action, thereby acknowledging parents' involvement in the decision (see also [21, 22]). By contrast, in this next excerpt reference is made to a single 'choice' about what is to be done.

\section{Extract 5 ('Single-option choice')}

$1 \quad$ Dr: What we all need $\mathrm{t}^{\prime}(0.5)$ really (1.0) decide as a team, (0.5)

$2 \quad>$ you know< all of us (.) the nursing staff, the junior doctors

3 myself, an' you (3.0) is $\uparrow$ knowing (0.4) everything we know

$4 \quad$ about her start in life (.) an' the fact that we $<(0.6)^{\circ}{ }^{\circ}$ have ${ }^{\circ}$

$5 \quad(0.3)>$ really< $(0.3)$ major concerns about, $(0.2)$ (which you

6 thought that)

$7 \quad(1.5)$

$8 \quad \mathrm{M}: \quad$.SNFF

$9 \quad(0.8)$

10 Dr: should she deteriorate, [ (1.5) ] would you want us

$11 \quad$ M: [hh. .hh. hh.]

12 Dr: (0.2) to bring the machine (0.5) pipe (pap) out [to pre]pare=

13 M: [Yeah.]

14 Dr: =the(airways.)

In this extract the doctor asks the parents whether a course of action (line 10) is something (you) would ... want us to do (line 8). In this format parents are offered only a single 'option' using a conditional format (should she deteriorate... would you want), though without referring to any alternatives. The conditional format is a characteristic feature of all cases in which only a 'singlechoice' is offered to parents. In the third format, presenting options, illustrated in excerpt 6, alternative courses of action are specified as options, and there is a clear indication that these are options for the parents to consider.

\section{Extract 6 (Options)}

1 Dr: So I guess from this point of view there's various options really.

$2 \quad(0.2)$ Uhm (0.6) .tch (0.5) one option is to carry on, with the

3 treatment (0.2) that we're doing? Just- (0.9) uhm (.) see what

4 happens,

((16 lines omitted))

21 Dr: .hhhhh (0.4) the other op- (0.2) the other option (0.2) would

22 be to $(0.5)$ decide as a- (0.2) as a group, including you obviously

23 that, (0.7) that he's been through enough an' that, (0.9) he's

24 not going to be able to recover.

The single (conditional) 'option' in extract 5 and one of the options in extract 6 are similar - to continue treatment with no expectation of recovery, or to cease treatment. But the formats are significantly different. The 'single-option 'choice' format, as in ex.5, does not allow for parental 
involvement in choosing between options, whereas 'options' are presented with alternatives, the decision between which will involve parents, as in ex.6. Hence the difference between 'single-option choice' and 'option (listing)' is in the different affordances of each format regarding parental involvement in decisions about their babies.

\subsection{Association between who initiates decision and format}

A significant association was found between these decision formats, and whether doctors or parents had initiated the decision points (two-tailed Fisher's exact $p=0.017$ ). When doctors initiate decision points they tend to introduce the decision by making a recommendation or using a 'single-option choice.' By contrast when parents have initiated the decision point, doctors tend to list possible 'options'; for a summary see table 2.

Table 2: Association between who initiated the decision point and the format of that decision

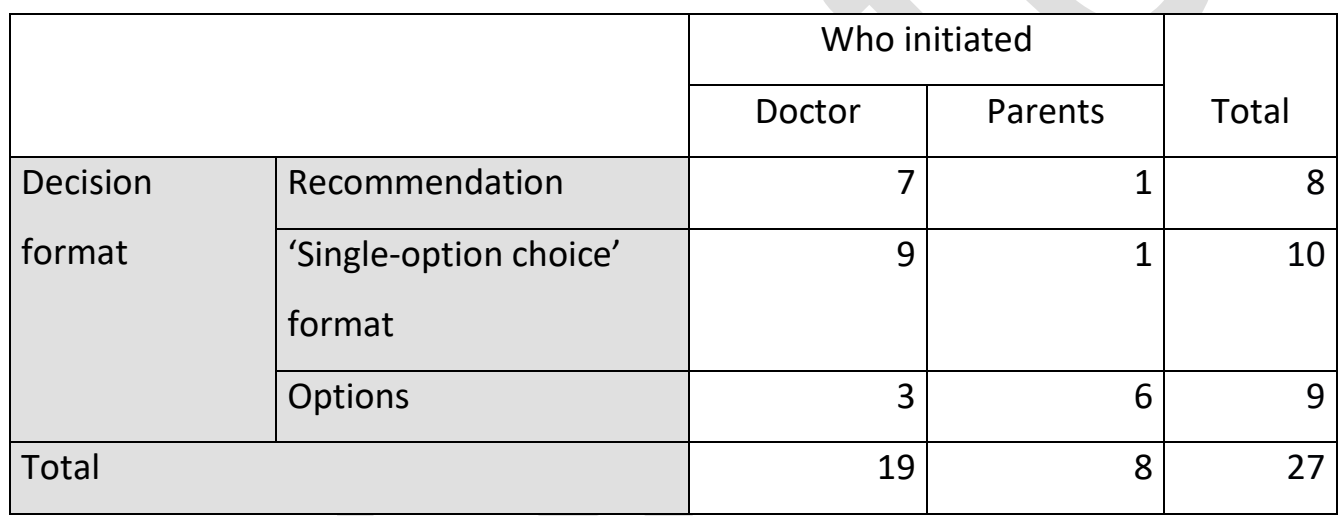

* Kappa for the agreement between Coder A and Coder B for 'who initiated the decision' was 0.85 , which indicates 'very good agreement.'

** Kappa for the interrater reliability between Coder A and Coder B for the decision format was 0.63 , which indicates 'good agreement.'

When the doctor initiates the decision point in extract 7 , he does so with a recommendation.

\section{Extract 7 [S2F19R1]}

1 Dr: There is a possibility that sh- (0.2) Ella might deteriorate in the 2 ventilator.

3 (1.2)

$4 \quad$ Dr: $\quad$ A:nd (0.7) die.

$5 \quad(0.8)$

$6 \mathrm{M}:{ }^{\circ} \mathrm{Mhm}$,

7 Dr: Okay?

$8 \quad(0.2)$

$9 \mathrm{M}:{ }^{\circ}$ Yeah. ${ }^{\circ}$

10 Dr: Uh I'm- I'm: I'm keeping- hh I'm giving you: (0.2) that

11 information so that you can process, (0.2) 


\begin{tabular}{|c|c|c|}
\hline 12 & M: & Yeah, yeah. \\
\hline 13 & & $(0.6)$ \\
\hline 14 & Dr: & Process the information, $>$ okay. $<=$ \\
\hline 15 & M: & $=\overline{\mathrm{M}} \mathrm{hm}$. \\
\hline 16 & & $(0.8)$ \\
\hline 17 & Dr: & Uh: (2.6) ehhh in: $y$-ahhh. should she: (0.3) deteriorate in \\
\hline 18 & & the vent- in the ventilator, $. \mathrm{HHH}<1$ don't think it's \\
\hline 19 & & appropriate,> (1.0) uh:: (0.8) phh. doing chest \\
\hline 20 & & compression, $(0.3)$ or: $(0.7)$ doing, $(0.8)$ uh:: \\
\hline 21 & & ma- giving medication to: (0.4) kick-start the heart. \\
\hline 22 & & $(0.2)$ \\
\hline 23 & M: & ${ }^{\circ} \mathrm{Mhm},{ }^{\circ}$ \\
\hline 24 & Dr: & Do you agree with that? \\
\hline
\end{tabular}

The doctor has informed the parents that the baby may deteriorate on the ventilator, and die (extract 7 lines 1-4). Should that happen, he recommended against life-sustaining treatment ("I don't think it's appropriate", lines 17-21). His recommendation ruled out continuing cardiac compressions and adrenaline (lines 18-21). He then directly sought the parents' agreement - using a form that expects agreement - for this course of (in)action (line 24). This delimited the affordances of this (recommendation) format, so far as the parents' response is concerned, whilst retaining an explicit orientation to the parents' right to be part of the decision.

An example of the single 'single-option choice' formats, the other format that tends to follow doctor-initiated decision points, was shown in Extract 3 above. The conditional form in line 57 conveys only a single 'choice' for the future (line 53), to limit further treatment if the baby is unable to breathe unaided by the ventilator. It is presented as something to consider (line 58), rather than a course of action that the doctor is directly proposing. The doctor's reference to 'we' in we do need to consider, (line 58) follows his reference to the medical team 'we' in we continue to do so (line 56); hence 'we' may be hearable as referring to the medical team, rather than as involving the parents.

Finally, the third format, in which doctors refer to or list options, tends to follow parentinitiated decision points, as here when the mother (who is audibly upset) asks so what's next (line 5).

\section{Extract 8 [F13R1]}

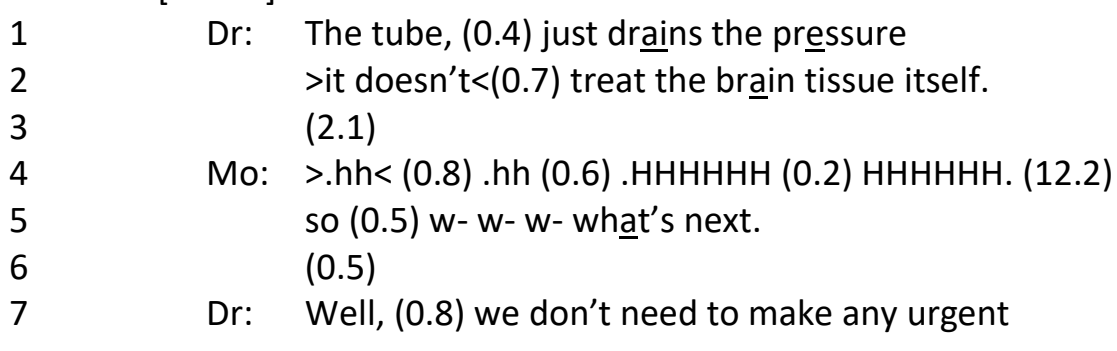


((45 lines omitted))

61

62

63

64

65

66

67 decisions but, (1.4) one option, in this situation $(0.6)$ is to, (0.5) consider whether it's actually right to continue with the intensive care support that she's, $+(0.4)$ she's having.

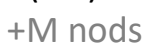

Dr: Would it actually be kinder to refocus on (1.2)

taking her off the breathing machine.

The doctor responded to the mother having initiated the decision point, by indicating that a decision did not have to be made right away (lines $7 / 8$ ) and that there were options - one being to consider suspending intensive care support (lines 8-11); then, after reiterating that there's no rush to make a decision (line 61), adding another option, to do another scan tomorrow (line 67). By responding directly to the mother's enquiry what's next (line 5), the doctor's reference to 'we' in we don't have to make any urgent decisions (lines 7/8) is inclusive - 'we' is compatible with including the parents along with the medical team. The doctor's explicit references to and listing of options in this excerpt, together with the hearable inclusivity of 'we', offered scope for the parents to be involved in making decisions, in the future, about their baby's treatment; this is what is meant by the affordances of this format, regarding parental involvement in decision making. We are currently investigating whether theses affordances are reflected in differences in parental participation.

\subsection{Association between who initiated, and type of decision}

Sequences were also coded according to the type of limitation to life-sustaining treatment (LST) presented. The decision types were categorized as 'withdrawing LST', 'withholding LST' and a 'do not resuscitate or DNR Order'. [5] Withdrawing life sustaining treatment refers to treatment that has already started such as ventilatory support. Withholding life-sustaining treatment refers to treatment that has not been started, which could mean surgery or other invasive procedures for example. A DNR order refers specifically to withholding procedures to restart the heart and breathing in the case of cardio-respiratory arrest,[5] including the use of both adrenaline and cardiac compressions. 
Table 3: Who initiated the decision point and the type of decision

\begin{tabular}{|c|c|c|c|c|}
\hline \multirow{2}{*}{\multicolumn{2}{|c|}{ 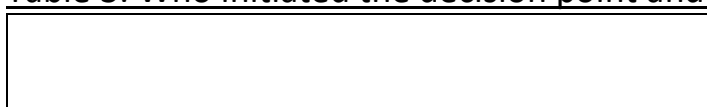 }} & \multicolumn{2}{|c|}{ Who initiated } & \multirow[b]{2}{*}{ Total } \\
\hline & & Doctors & Parents & \\
\hline \multirow[t]{3}{*}{ Decision type } & DNR & 2 & 0 & 2 \\
\hline & Withholding LST & 11 & 1 & 12 \\
\hline & Withdrawing LST & 6 & 7 & 13 \\
\hline \multicolumn{2}{|l|}{ Total } & 19 & 8 & 27 \\
\hline
\end{tabular}

We found a significant association between who initiates the decision point and the type of limitation decision: (two-tailed Fisher's exact $p=0.030$, see table 3. Doctor initiations encompassed all three types of decisions, whereas parent initiations overwhelmingly concern decisions about withdrawing ventilatory support (in 7 out of 8 cases). In the case of withdrawal of LST, the deterioration was currently happening, or the prognosis was known to be very poor and therefore the issue of 'what next' was perhaps more predictable. In the case of withholding LST, the cases all concerned possible clinical deterioration, including one unexpected possibility of not performing surgery, and therefore the decision to withhold life-sustaining treatment is perhaps less likely to be anticipated by a parent.

\section{Discussion and Conclusion}

\subsection{Discussion}

Making end-of-life decisions about newborn babies poses immense challenges for both parents and the health care team. According to all guidance, it is imperative that parents fully understand the implications of a doctor's explanation of the prognosis for their baby (a poor outcome), so that they are enabled to play an active and informed role in determining the course(s) of action to be taken in the future; in some cases that future may be limited, even to a few hours in some of our recorded cases. Through our analysis of real time consultations between doctors and parents in neonatal intensive care, we have identified the moments at which a decision about 'what to do next' is initiated - key moments in the conversations about how best to treat a very ill baby moments when the implications of the baby's ill health and poor prognosis become consequential for the baby's future treatment. At this point, either parents or doctors display their recognition that the point has been reached at which a decision should be made.

A pattern emerges in which doctors initiate decision points if the parents have not already done so. As the doctor is explaining the baby's poor prognosis, the parents may understand where this is heading and choose to step in to ask 'what's next' (e.g. extract 1). However, having quite fully 
explained the baby's poor condition, if the parents have not initiated the decision point, doctors may then initiate the matter of what should be done. This pattern implies that when parents initiate decisions, there is a certain alignment between doctors and parents, as regards the baby's prognosis and the implications of the diagnostic news that the doctor is reporting. When the mother asks 'what's next' in that extract, she is not thereby implying that there is any active treatment that could necessarily save her baby. In short, when parents initiate decision points, they may be displaying alignment with the trajectory of the doctor's account of the baby's poor prognosis. [23] By contrast, when doctors initiate the decision alignment may not have been achieved either because parents may resist the trajectory of the news, or parents have not yet been able to forecast the implications of the doctor's account of the babies deterioration. This latter point may explain why parents tended to initiate when the decision was about withdrawal of LST, where the baby's poor clinical condition/prognosis was current and ongoing, as opposed to those cases involving hypothetical future deterioration. A next stage in our research will be to investigate whether and how parental affiliation is expressed, under what circumstances alignment between doctors and parents is not achieved, and what are the consequences for decision-making of alignment or non-alignment.

Our analysis shows that whether it is the doctor or parent who initiates the decision point has consequences for how the doctor subsequently presents the decision about limiting LST. When doctors initiate a decision about limiting LST, they do so using a recommendation or the 'singleoption choice' format. By contrast, when parents initiate the decision moment, the doctor tends then to list or refer to options. We previously found that the way in which a decision to limit lifesustaining treatment is presented by doctors has important implications for the extent to which parents are given the opportunity to ask questions and assert their preference.[14] In particular, we found that providing options as opposed to recommendations was associated with more purposeful parental participation (i.e. neither passive nor confrontational) [14] in the decision-making process. This association is not straightforward, however, and decision-making practices can be used in variable ways, resulting in both different opportunities for parents to respond, $[24,25,26,27]$ and self-reports indicating the perception of choice. [24, 26] Furthermore, the doctor's use of one decision format over another may be related to clinical considerations, or the type of decision being presented. [27-30] In the specific case of selecting between option listing and recommending, neurologists in outpatient clinics appear to choose recommendations when the risks were higher and, in particular when there was uncertainty about the diagnosis.[30] In a study of decision making in outpatient psychiatric consultations in Japan, explicit proposals that create a decision moment (in comparison to implicit alternatives) occurred in those sequences in which the decision was aligned to the patients' perspective. [31] The selection of one format over another may concern a more local 
issue of the risk of patient resistance. When parents initiate decisions about future courses of actions in neonatal care, it may be that doctors are inclined to honour that active engagement with an explicit mention of options.

We have identified three decision formats, in which doctors i) recommend what should be done, according to their view and that of the medical team; ii) indicate only a 'single-option choice' to take a certain course of action (i.e. where the doctor presents a course of action which is dependent on parental choice, without explicitly referring to or listing available choices); and iii) refer to, possibly listing, and outlining alternative options. The third of these formats, option listing, is the most clearly designed to involve the parents in considering their preference(s) about what should be done. In other words, reference to and listing options facilitates the opportunity for parents to consider the implications of each. By contrast, when doctors recommend a course of action or less explicitly present something akin to choice, but without alternative options from which to choose, the affordances of those formats militate against parental involvement in making decisions about their baby's treatment. Further research is needed to explore more fully the implications of one format over another in terms of a broader notion of shared decision making. We have considered the extent to which parents are able to express their preference and ask questions in the immediate talk that follows; there may be other facets of the parent's response to be considered. By investigating how alignment is achieved prior to the decision moment, we will also contribute to an analysis of shared decision making in a way that goes beyond the narrower focus of the way in which the decision itself is presented.[32]

Notwithstanding the caveats outlined above, our findings suggest that providing parents with options, rather than directly recommending a course of action, can provide parents the opportunity to present their preference[14, 33], and can be more conducive to their alignment and shared decision-making, $[14,29,34]$

\section{Limitations}

The analysis is based on a relatively small sample; however, it does reveal a clear and statistically significant difference in patterns of association between parent- and doctor-initiated decision points and the formats through which doctors frame the possible decision(s) about course(s) of action. Further research is necessary into: whether the formats we have identified are associated, in the ways we suggest, to greater or lesser parental involvement in decision-making; whether parental alignment in the interaction leading up to a decision point is associated with specifically parental initiation of decision points; and what communicative factors in the doctor's emerging account of a baby's poor health status/prognosis are associated with parental alignment. 


\subsection{Conclusion}

Our research into life limiting discussions in neonatal intensive care units (NCIUs) is based on real time data collected in two large NCUIs, in different regions of England. Parents from different cultural and ethnic backgrounds were involved in the study, as were (female and male) senior neonatal doctors; hence our findings are applicable to a wider population. Our findings show strong associations between whether parents or doctors initiate the moment of moving to a decision about end-of-life treatment for newborn babies, and the formats with which doctors frame possible decision(s). When parents initiate decision points, doctors tend subsequently to offer options, outlining alternative courses of action. In contrast, when doctors initiate decision points, they tend subsequently to make recommendations about what they and their medical teams think should be done, or present a possible course of action. It was also evident that doctors tended to initiate the decision point in the case of a DNR (do not resuscitate) or withholding life support care, should the baby's condition not respond to present treatment or worsen; whilst by contrast when parents initiated the decision point, it tended to be in the case of withdrawing such care.

\subsection{Practice Implications}

It will be important for neonatal doctors to consider the asymmetry evident in these findings, that if they initiate decisions about the future treatment of babies with poor prognoses they may frame those decisions in forms that serve to limit the role of parents in decision-making. Opening up decisions by explicitly proposing options provides parents with opportunities to be involved in decisions about how best to treat their very ill infants, and thereby fostering shared decision making.

\section{Acknowledgments}

We are most grateful to the parents and doctors who allowed us to record and analyse these profoundly difficult conversations.

\section{References}

[1] N. Feeley, P. Zelkowitz, C. Cormier, L. Charbonneau, A. Lacroix, A. Papageorgiou, Posttraumatic stress among mothers of very low birthweight infants at 6 months after discharge from the neonatal intensive care unit, Appl. Nurs. Res. 24(2) (2011) 114-117. [2] A. Janvier, J. Lantos, J. Aschner, K. Barrington, B. Batton, D. Batton, S.F. Berg, B. Carter, D. Campbell, F. Cohn, A.D. Lyerly, D. Ellsbury, A. Fanaroff, J. Fanaroff, K. Fanaroff, S. Gravel, M. Haward, S. Kutzsche, N. Marlow, M. Montello, N. Maitre, J.T. Morris, O.G. Paulsen, T. Prentice, A.R. Spitzer, Stronger and More Vulnerable: A Balanced View of the Impacts of the 
NICU Experience on Parents, Pediatrics 138(3) (2016) e20160655, DOI: 10.1542/peds.20160655.

[3] S. Yaman, N. Altay, Posttraumatic stress and experiences of parents with a newborn in the neonatal intensive care unit, J. Reprod. Infant. Psyc. 33(2) (2015) 140-152.

[4] N. Aladangady, C. Shaw, K. Gallagher, E. Stokoe, N. Marlow, Short-term outcome of treatment limitation discussions for newborn infants, a multicentre prospective observational cohort study, Arch. Dis. Child Fetal Neonatal Ed. 102(2) (2017) F104-F109.

[5] V. Larcher, F. Craig, K. Bhogal, D. Wilkinson, J. Brierley, Royal College of Paediatrics and Child Health, Making decisions to limit treatment in life-limiting and life-threatening conditions in children: a framework for practice, Arch. Dis. Child 100 Suppl. 2 (2015) s3-23. [6] D. Wilkinson, R. Truog, J. Savulescu, In Favour of Medical Dissensus: Why We Should Agree to Disagree About End-of-Life Decisions, Bioethics 30(2) (2016) 109-118.

[7] K. Gallagher, N. Marlow, A. Edgley, D. Porock, The attitudes of neonatal nurses towards extremely preterm infants, J. Adv. Nurs. 68(8) (2012) 1768-1779.

[8] K. Gallagher, N. Aladangady, N. Marlow, The attitudes of neonatologists towards extremely preterm infants: a Q methodological study, Arch. Dis. Child Fetal Neonatal Ed. 101(1) (2016) 31-6.

[9] Nuffield Council on Bioethics, Disagreements in the care of critically ill children, Bioethics briefing note, 2019.

[10] L. Gillam, J. Sullivan, Ethics at the end of life: who should make decisions about treatment limitation for young children with life-threatening or life-limiting conditions?, J Paediatr. Child H. 47(9) (2011) 594-8.

[11] L. Caeymaex, M. Speranza, C. Vasilescu, C. Danan, M.M. Bourrat, M. Garel, C. Jousselme, Living with a crucial decision: a qualitative study of parental narratives three years after the loss of their newborn in the NICU, PloS one 6(12) (2011) e28633.

[12] M.A. de Vos, A.P. Bos, F.B. Poltz, M. van Heerde, B.M. de Graaff, K. Tates, R.D. Truog, D.L. Willems, Talking With Parents About End-of-Life Decisions for Their Children, Pediatrics 135(2) (2015) E465-E476.

[13] R.D. Boss, P.K. Donohue, S.M. Larson, R.M. Arnold, D.L. Roter, Family Conferences in the Neonatal ICU: Observation of Communication Dynamics and Contributions, Pediatr. Crit. Care Me. 17(3) (2016) 223-30.

[14] C. Shaw, E. Stokoe, K. Gallagher, N. Aladangady, N. Marlow, Parental involvement in neonatal critical care decision-making, Sociol. Health III. 38(8) (2016) 1217-42.

[15] G. Jefferson, Glossary of transcript symbols with an introduction, in: G. Lerner (Ed.), Conversation analysis: studies from the first generation, John Benjamins, Amsterdam, 2004, pp. 13-31.

[16] P. Drew, Conversation Analysis, in: K.L. Fitch., R.E. Sanders. (Eds.), Handbook of Language and Social Interaction, Lawrence Erlbaum, Mahwah, NJ, 2005, pp. 71-102. [17] J. Sidnell, Basic conversation analytic methods, in: J. Sidnell \&.T. Stivers (Eds.), The handbook of conversation analysis, Wiley-Blackwell, Oxford, 2012, pp. 77-99.

[18] J.D. Robinson, A. Tate, J. Heritage, Agenda-setting revisited: When and how do primarycare physicians solicit patients' additional concerns?, Patient Educ Couns 99(5) (2016) 71823.

[19] N. Marlow, C. Shaw, K. Connabeer, N. Aladangady, K. Gallagher, P. Drew, E. Stokoe, Introducing end-of-life decisions in neonatal care - a conversation analytic study (Under Review). 
[20] T. Stivers, J. Heritage, R.K. Barnes, R. McCabe, L. Thompson, M. Toerien, Treatment Recommendations as Actions, Health Commun 33(11) (2018) 1335-44.

[21] T. Stivers, Parent resistance to physicians' treatment recommendations: One resource for initiating a negotiation of the treatment decision, Health Commun 18(1) (2005) 41-74.

[22] C.J. Koenig, Patient resistance as agency in treatment decisions, Soc Sci Med 72(7) (2011) 1105-14.

[23] T. Stivers, Stance, alignment, and affiliation during storytelling: When nodding is a token of affiliation, Res. Lang. Soc. Interac. 41(1) (2008) 31-57.

[24] M. Reuber, M. Toerien, R. Shaw, R. Duncan, Delivering patient choice in clinical practice: a conversation analytic study of communication practices used in neurology clinics to involve patients in decision-making, Health Serv. Deliv. Res. (2015) 3(7).

[25] M. Toerien, R. Shaw, R. Duncan, M. Reuber, Offering patients choices: a pilot study of interactions in the seizure clinic, Epilepsy Behav. 20(2) (2011) 312-20.

[26] M. Toerien, M. Reuber, R. Shaw, R. Duncan, Generating the perception of choice: the remarkable malleability of option-listing, Sociol. Health IIIn. 40(7) (2018) 1250-67.

[27] A. Tate, B.J. Rimel, The duality of option-listing in cancer care, Patient Educ. Couns.

(2019) https://doi.org/10.1016/j.pec.2019.07.025

[28] P.L. Hudak, S.J. Clark, G. Raymond, How surgeons design treatment recommendations in orthopaedic surgery, Soc. Sci. Med. 73(7) (2011) 1028-36.

[29] A. Quirk, R. Chaplin, P. Lelliott, C. Seale, How pressure is applied in shared decisions about antipsychotic medication: A conversation analytic study of psychiatric outpatient consultations, Sociol. Health III. 34(1) (2012) 95-113.

[30] P. Chappell, M. Toerien, C. Jackson, M. Reuber, Following the patient's orders?

Recommending vs. offering choice in neurology outpatient consultations, Soc. Sci. Med. 205 (2018) 8-16.

[31] S. Kushida, Y. Yamakawa, Fitting proposals to their sequential environment: a comparison of turn designs for proposing treatment in ongoing outpatient psychiatric consultations in Japan, Sociol. Health IIIn. 37(4) (2015) 522-44.

[32] M. Reuber, P. Chappell, C. Jackson, M. Toerien, Evaluating nuanced practices for initiating decision-making in neurology clinics: a mixed-methods study, Health Serv. Deliv. Res. 2018, 6(34).

[33] M. Toerien, R. Shaw, R. Markus, Initiating decision-making in neurology consultations: 'Recommending' versus 'option-listing' and the implications for medical authority, Sociol. Health IIIn. 35(6) (2013) 873-90.

[34] K. Ekberg, A. LeCouteur, Co-implicating and re-shaping clients' suggestions for behavioural change in cognitive behavioural therapy practice, Qual. Res. Psychol. 11(1) (2014) 60-77. 